Review Article

\title{
The Practice of Automated Drug Dispensing Technology on the Reduction of Medication Errors in the Medication Process
}

\author{
Harshita Gupta*, Nandini Chaudhary \\ Department of Pharmacy, Pranveer Singh Institute of Technology, Kanpur, India. \\ *Corresponding author's E-mail: harshitagupta7772@gmail.com
}

Received: 08-04-2021; Revised: 12-09-2021; Accepted: 21-09-2021; Published on: 15-10-2021.

\begin{abstract}
This review is used to describe the automated dispensing systems increasing opportunities for improving the health care system. Safe automated dispensing systems (ADS) were suitable for providing a patient's medication therapy when pharmacists are caregivers. This review highlights the use of time-saving technologies such as automated dispensing machines, automated dispensing cabinets, and robotic original pack dispensing systems which have been suggested as potential mechanisms for reducing medication errors, improve accuracy, safety, and efficiency of medication dispensing. The implementation of automated dispensing machines improves the quality of the medication distribution process as compared with Manual Dispensing System. This review also emphasizes the impact of new emerging technologies of an automated dispensing system (ADS) on reducing medication errors and ADE. The Automated dispensing system is a key strategy of improving patient safety through increasing interaction between the patient and pharmacist, resulting in a chance for pharmacists to carry out new clinical functions. This review focus on the practices of automated drug dispensing in different terms in order to reduce the medication errors drug medication process.
\end{abstract}

Keywords: Automated dispensing system, Medication error, Automated dispensing machine, Decentralized system, Automated dispensing cabinet, Robotic original pack dispensing system.

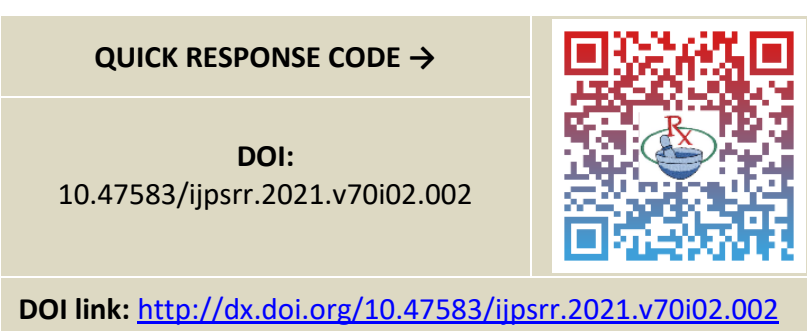

\section{INTRODUCTION}

$\mathrm{n}$ recent years, Pharmacists includes various technologies for labour-intensive and time-consuming processes to prepare and distribute medicines. It is reported that both centralized dispensing pharmacies and inpatient care units will grow through the technology which automates drug distribution. ${ }^{1}$ Safe automated dispensing systems (ADS) are used for ethical pharmacy practice by providing a patient's medication therapy. ADS are an appropriate way for patients to receive the medicine only when pharmacists are caregivers. The safest automated dispensing systems were achieved by the "five rights" - right drug, right dose, right patient, right route, and the right time. ${ }^{2,3}$ In 1991, The University Hospital Consortium promotes a "technology statement" upon the automation of services which summarizes that "Strategic plan elements which increase personnel productivity are highly fascinating to attain the organization's financial objectives. In today's strategic plan, Drug delivery automation can be a necessary part of controlling personnel expenses in the hospital pharmacy and the nursing's budget part is responsible for the administration and charting of drugs. ${ }^{4}$ Currently, automated drug distribution systems (ADDS) were manufactured by Pyxis, Inc., and Omnicell, Inc. was implying a change in drug distribution started in the 1960s in the United States as unit-dose systems. Unit-dose systems were replaced with a previous approach referred to as multiple-dose drug distribution systems. When nurses had whole responsibility for the overall medication system, from administering multiple doses of the drug to dose preparation termed as Multidose systems. Whereas, in Unit-dose systems, nurses provide single packaged and labelled doses with a duration of more than 8-hour intervals under the administration schedule. ${ }^{5,6}$ Due to this, unit-dose systems reduced the chances of medication errors, time management of pharmacists as well as nurses, and dosing frequency is reduced. 7-10 Automated dispensing systems (ADS) were divided into three categories i.e., point-of-care, decentralized, and centralized. Decentralized systems generally occur outside the control of pharmacist's while the pharmacist must still identify correction of the various steps by ensuring the right drug dose availability in the right location in a dispensing cabinet through accessing the storage cabinet by the caregiver to which the right dose is accurately administered to the right patient. Point-of-care systems are as same as decentralized systems. Pharmacists were in direct control of the dispensing process in Centralized systems. ADS development involves three goals i.e., a) By utilizing rapid developing technology into a safe medication process, b) Direct patient care by the pharmacists, c) Minimization of cost. 11,12 Today, automation in drug dispensing includes packaging of drugs, controlling software, computer-assisted physician order 
entry, dispensing cabinets, the automated generation of customizable forms and reports, and robotic handling. ${ }^{13}$

\subsection{Automated Dispensing Technologies}

There are various automated dispensing technologies present in the market such as

a) Automated Dispensing Machine (ADM),

b) Automated dispensing cabinets, and

c) Robotic original pack dispensing system.

\subsubsection{Automated Dispensing Machine (ADMs)}

The implementation of the Automated Dispensing Machine (ADMs) in the dispensing process involves improving the quality of the medication distribution process and the effective utilization of human resources. ${ }^{14}$ It was reported that ADMs reduced the dispensing time of pharmacists ${ }^{15-17}$ but pharmacists needed more time to provide more intelligent services like patient care-related activities.

\section{Comparison between Manual Dispensing System/ Automated Dispensing System/ Modified Automated Dispensing System}

\section{Manual Dispensing System (Manual system)}

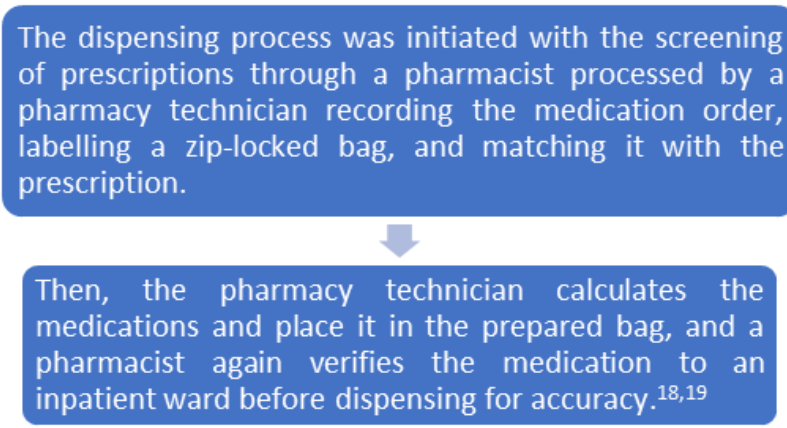

Figure 1: Work process of Manual Dispensing System.

\section{Automated Dispensing System (ADM system)}

Initially, a prescription was

checked by a pharmacist for

the dispensing process and

recorded by a pharmacy

technician.
Then a pharmacist verified

the prescription and data

was transferred to the ADM

for preparation.
The medications were filled through the ADM in unit dose packages, and automatically a label was printed and placed on each unit dose package.
Then a pharmacist proceeds the final verification before delivery of the unit dose medicines to the inpatient ward. A pharmacist utilizes the ADM system for monitoring the filling of medication into the machine, while a pharmacy technician was responsible for these tasks in the manual system. ${ }^{[20-24]}$

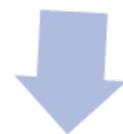

pharmacy technician with the help of the ADM cut the strippackaged medication for each patient, matched it with the prescription, and screened for the flexibility of the dispensed unit dose.

Figure 2: Work process of Automated Dispensing System.

\section{Modified Automated Dispensing System (Modified ADM system)}

The modified ADM system minimizes the dispensing process and reduces the human resource requirement along with improving the quality of patient care by utilizing the work process of the ADM system.

The ADM system was modified to increase the efficiency of the ADM system for decreasing the workload, and designed to cover functions as stock management and dispensing.

The final screening of the dispensing process for the accuracy of the medication before its delivery to the inpatient ward was conducted by a pharmacy technician with no involvement of the pharmacist.

The pharmacy technician manages the ADM for filling of medications concerning stock management. ${ }^{25-27}$

Figure 3: Work process of Modified Automated Dispensing System. 


\subsubsection{Automated dispensing cabinet (ADCs)}

Automated dispensing cabinets were also referred to as automated distribution devices which were prepared not only to prevent the errors and replace human activity but also to support humans in clinical decision making. ${ }^{14}$ ADCs must identify the risks and promote the safe practice of reducing medication errors. ADC was utilized for different decentralized drug distribution including in outpatient areas, like the emergency department.

$A D C$ has the potential for providing safety advantages such as improving efficiency among pharmacy and nursing disciplines, and the capacity to monitor inventory and hinder drug deviation through accurate medication tracking and record-keeping. ADC was significant for the use of patient profiling systems to pull out medication which allows the withdrawal of medication after pharmacist order verification through the patient's primary nurse only by interfacing with the pharmacy information system. ${ }^{28-30}$

\subsubsection{Robotic dispensing system}

Robotic original pack dispensing system has been recommended for improving safety, performance, and enhancing the storage capacity to which it stores and retrieves automatically the medication depending upon the barcode on the product. The rate of dispensing errors was reduced by the implementation of a robotic original pack dispensing system and optimized stock management. While dispensing robots do not handle all the packages so, residual manual dispensing was also utilized in the post robotization phase but in both the phase the original packs were directly delivered by the technicians to the patient without previous labelling. At the pre-implementation phase, a barcode-controlled system was used for dispensing the drug manually by the technicians while the dispensing robot ROWA Vmax (ARX) was utilized at the post-implementation phase for dispensing the drug. ${ }^{31-34}$

\subsection{Impact of technologies on reducing medication errors and ADEs}

The new emerging technologies such as computerized medication administration records (CMARs), computerized physician order entry (CPOE), automated dispensing machines (ADMs), and barcoding has a potential effect in reducing medication errors and adverse drug events $(\mathrm{ADEs})^{35}$ as shown in Fig 4.

\begin{tabular}{|l|}
\hline \multicolumn{1}{|c|}{ CMARs } \\
\hline - Computerized \\
medication \\
administration \\
records (CMARs) \\
have the potential to \\
maintain consistency \\
in medication \\
documentation, \\
accuracy in dosage \\
information, and \\
clear records of \\
administration. ${ }^{[36]}$ \\
This technology \\
enhances \\
productivity through \\
printouts of labels, \\
full lists, and using \\
reports. \\
\hline
\end{tabular}
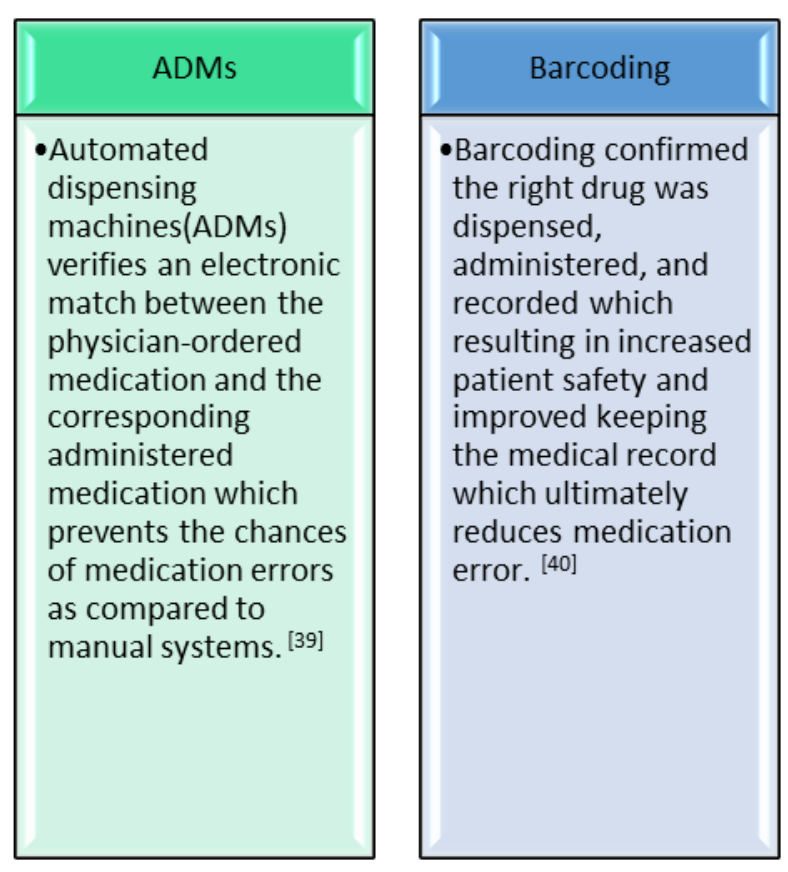

Figure 4: Effect of technologies on medication error and ADEs

\subsection{Insight to reduce the medication error by the implementation of automated drug dispensing:}

Chapuis et $\boldsymbol{a l}$ evaluated the automated dispensing system which impacts the incidence of medication errors associated with preparation, administration, and picking of drugs in a medical intensive care unit and estimated the clinical significance of such errors and user satisfaction.

Design: Post-intervention and pre-intervention study consisting of control along with an intervention medical intensive care unit.
Setting: 2,000- bed university hospital was conducted under two medical intensive care units.

Patients: Adult medical intensive care patients.

Interventions: The implementation of an automated dispensing system was chosen randomly in a study unit after a 2-month observation, with other units was remaining under control. Measurements and Main

Results: The rate for overall error was indicated by percentages which were categories by an expert committee under the National coordinating Council for Medication 
Error Reporting and Prevention. Self-administered questionnaires were assessed by nurses for user satisfaction. Hence, a total of 1,476 medications for 115 patients were observed. In this study, it was examined that after implementation of the automated dispensing system, a reduced percentage of total opportunities for error was observed compared to the control unit $(13.5 \%$ and $18.6 \%$, respectively; $p<.05)$, therefore, no significant difference was noticed before the implementation of the automated dispensing system (20.4\% and $19.3 \%$, respectively; not significant). Thus, in this study, a significantly reduced percentage of total opportunities for error was noted before-and-after comparison $(20.4 \%$ and $13.5 \%$; $p<.01)$. The impact of the automated dispensing system in reducing preparation error $(p<.05)$ was analysed significantly for error. Finally, for working conditions, the mean was improved from1.0-0.8 to 2.5-0.8 on the four-point Likert scale.

Outcomes: overall medication errors accompanied to preparation, administration, and picking of drugs were reduced by the implementation of an automated dispensing system in the intensive care unit. Additionally, the new drug dispensation organization was favoured by more nurses. ${ }^{41-50}$

Cousein et al analysed the automated drug distribution system and their impact on medication errors (MEs).

Methods: Observational study before and after in a Valenciennes, France 40-bed short-stay geriatric unit within an 1800 bed general hospital. When the drug distribution system changed before and after from ward stock system (WSS) to a unit dose dispensing system (UDDS), thus researchers had examined the nurses' medication administration rounds and compared to the prescribed drugs through the integration of unit dose dispensing robot and automated medication dispensing cabinet (AMDC).

Results: It was evaluated that about 148 patients were observed total 615 opportunities of errors (OEs) treated during the ward stock system (WSS) period thereby; among 166 patients observed 783 OEs were treated during unitdose dispensing system (UDDS) period. Thus, the two periods were compared and calculated by medication administration error (MAE). In addition, type of errors, risk reduction as well as the seriousness of errors was measured for the patients. Hence, an automated drug dispensing system was estimated and show results in a $53 \%$ reduction in MAEs where all type of error was minimized in the UDDS period than in the WSS period $(P<0.001)$. Thus, there was a reduction of $79.1 \%$ in the wrong dose and $93.7 \%$ in wrong drug errors respectively.

Outcomes: The medication safety was improved among the elderly by the implementation of an automated UDDS due to the combining effect of unit dose dispensing robot and automated medication dispensing cabinet (AMDCs) significantly reduces discrepancies between ordered and administered drugs. ${ }^{51-59}$
Lisby et al investigate the type, frequency, and consequence of medication error in more stages of medication process including discharge summaries.

Design: three methods i.e. direct observations, unannounced control visits, and chart reviews were utilized to detect the errors in the medication process under crosssectional study. Thus, all potential medication error and their consequences were evaluated by physicians and pharmacists in discharge summaries.

Setting: A randomly selected medical and surgical department at Aarhus University Hospital, Denmark.

Study participants: In this, the age group i.e. 18 or over $(n=64)$ were eligible in hospital patients where nurses were dispensing and administering the drugs and physicians prescribing the drugs.

Main outcome measures: Clinical consequences of all detected errors and their frequency, type, and potential were compared with the total number of opportunities for error.

Results: Here, about 2467 opportunities for errors detected about 1065 errors in the medication process assessed as potential adverse drug events. Thus, the frequency of medication errors at each stage was ordering $39 \%$, transcription: $56 \%$, dispensing: $4 \%$, administration: $41 \%$, and at last discharge summaries: $76 \%$. Hence, due to the lack of drug form, the omission of drug/dose, unordered drug and lack of identity control were common types of error occur throughout the medication process.

Outcomes: By the implementation of automated drug dispensing technologies in the medication process, the number of errors could be reduced through the involvement of simple changes of existing procedures and their quality was improved up to $50 \%$ reduced all errors in dose and prescriptions in the medication process. ${ }^{60-68}$

\section{CONCLUSION}

Automated dispensing systems revolutionize the health care system with the improvement in the quality of the medication dispensing process by utilizing time-saving automated dispensing technologies. The quality of the medication distribution process was improved with the implementation of the Automated Dispensing Machine (ADMs). Different automated dispensing technologies have the potential for reducing medication errors, improving safety, enhancing the efficiency, and accuracy of the dispensing process. Hence, this review concluded the practices of automated drug dispensing technologies on the reduction of medication error during the medication process as by the implementation of the automated dispensing system reduced overall medication errors related to picking, preparation, and administration of drugs. By the implementation of an automated UDDS due to the combining effect of unit dose dispensing robot and automated medication dispensing cabinet (AMDCs) significantly reduces discrepancies between ordered and administered drugs. By the implementation of automated 
drug dispensing technologies in the medication process, the number of errors could be reduced through the involvement of simple changes of existing procedures, and their quality was improved up to $50 \%$ reduced all errors in dose and prescriptions in the medication process.

\section{REFERENCES}

1. Rawley MG, Nickman NN, Jorgenson JA, Work activities before and after implementation of an automated dispensing system, Am J Health-Syst Pharm, 1996; 53:548-554, doi: 10.1093/ajhp/53.5.548; PMID: 8697015

2. Ferencz N, Safety of Automated Dispensing Systems, US Pharm, 2014; 39(8):8-12, doi: https://www.uspharmacist.com/article/safety-ofautomated-dispensing-systems

3. Simborg DW, Derewicz HJ, A highly automated hospital medication system, Five years' experience and evaluation, Annals internal med, 1975; 83:342-346, doi: 10.7326/00034819-83-3-342; PMID: 1180430

4. Hynniman $\mathrm{CE}$, Conrad WF, Urch WA, A comparison of medication errors under the University of Kentucky unit dose system and traditional drug distribution systems in four hospitals, Am J Hospital Pharm, 1970; 27: 802-814, PMID: 5473470

5. Riley AN, Derewicz HJ, Lamy PP, Distributive costs of a computer-based unit dose drug distribution system, Am J Hospital Pharm, 1973; 30:213-219, PMID: 4690479

6. Shultz SM, White SJ, Latiolais C J, Medication errors reduced by unit-dose, Hospitals, 1973; 47:106-112, PMID: 4706537

7. Balka E, Nutland K, Automated Drug Dispensing Systems: Literature Review, Action for health, 2004;6: 1-23, doi: https://www.researchgate.net/publication/277153453 Aut omated Drug Dispensing Systems Literature Review/link/ 56670f8a08ae34c89a0224a1/download

8. Brookins L, Burnette MBA, Cooley TW, ASHP guidelines on the safe use of automated dispensing devices, Am J Health Syst Pharm, 2010; 67: 483-90, doi: 10.2146/sp100004, PMID: 20208056

9. Wise LC, Bostrom J, Crosier JA, Cost-benefit analysis of an automated medication system, Nurs Econ, 1996;14:224-31, doi: 10.1016/i.jval.2017.03.001 , PMID: 28712617

10. Guerrero RM, Nickman NA, Jorgenson JA, Work activities before and after implementation of an automated dispensing system, Am J Health Syst Pharm, 1996; 53:548-54, doi: 10.1093/ajhp/53.5.548, PMID: 8697015

11. Schwarz HO, Brodowy BA, Implementation and evaluation of an automated dispensing system, Am J Health Syst Pharm, 1995;52:823-8, doi: 10.1093/ajhp/52.8.823, PMID: 7634117

12. Noparatayaporn $P$, Sakulbumrungsil $R$, Thaweethamcharoen $T$, Comparison on Human Resource Requirement between Manual and Automated Dispensing Systems, Value in health regional issues, 2017; 5: 107 - 111, doi: 10.1016/i.vhri.2017.03.007 PMID: 28648307

13. Findlay R, Webb A, Lund J, Implementation of advanced inventory management functionality in automated dispensing cabinets, Hosp Pharm, 2015; 50(7): 603-608, doi: 10.1310/hpj5007-603 PMID: 26448672
14. McCarthy Jr BC, Ferker M, Implementation and optimization of automated dispensing cabinet technology, Am J Health Syst Pharm, 2016; 73(19): 1531-1536, doi: 10.2146/ajhp150531 PMID: 27646814

15. Fanning L, Jones N, Manias E, Impact of automated dispensing cabinets on medication selection and preparation error rates in an emergency department: a prospective and direct observational before-and-after study, J Eval Clin Pract, 2016; 22(2): 156-163, doi: 10.1111/jep.12445 PMID: 26346850

16. Grissinger $M$, Safeguards for using and designing automated dispensing cabinets, P T, 2012; 37(9): 490-530, PMID: $\underline{23066340}$

17. Roman C, Poole S, Walker C, A "time and motion" evaluation of automated dispensing machines in the emergency department, Australas Emerg Nurs J, 2016; 19(2): 112-117, doi: 10.1016/i.aenj.2016.01.004 PMID: 26987705

18. Billstein-Leber M, Carillo CJD, Cassano AT, ASHP guidelines on preventing medication errors in hospitals, Am J Health Syst Pharm, 2018; 75(19): 1493-1517, doi: 10.2146/ajhp170811 PMID: 30257844

19. Leape LL, Brennan TA, Laird N, The nature of adverse events in hospitalized patients, Results of the Harvard Medical Practice Study II, N Engl J Med, 1991; 324: 377-384 The nature of adverse events in hospitalized patients, Results of the Harvard Medical Practice Study II, doi: 10.1056/NEJM199102073240605 PMID: 1824793

20. Bates DW, Cullen DJ, Laird N, Incidence of adverse drug events and potential adverse drug events, Implications for prevention, ADE Prevention Study Group, JAMA, 1995; 274:29-34, PMID: 7791255

21. Taxis K, Dean B, Barber N, Hospital drug distribution systems in the UK and Germany a study of medication errors, Pharm World Sci, 1999; 21:25-31, doi: 1023/a:1008616622472, PMID: 10214665

22. Anselmi ML, Peduzzi $M$, Dos Santos $C B$, Errors in the administration of intravenous medication in Brazilian hospitals, J Clin Nurs, 2007; 16:1839-1847, doi: 10.1111/j.1365-2702.2007.01834.x, PMID: 17880472

23. Barker KN, Flynn EA, Pepper GA, Medication errors observed in 36 health care facilities, Arch Intern Med, 2002; 162: 18971903, doi: 10.1001/archinte.162.16.1897, PMID: 12196090

24. Calabrese AD, Erstad BL, Brandl K, Medication administration errors in adult patients in the ICU, Intensive Care Med, 2001; 27:1592-1598, doi: 10.1007/s001340101065, PMID: 11685299

25. Rothschild JM, Landrigan CP, Cronin JW, The Critical Care Safety Study: The incidence and nature of adverse events and serious medical errors in intensive care, Crit Care Med, 2005; 33:1694-1700, doi: 10.1097/01.ccm.0000171609.91035.bd, PMID: 16096443

26. Fahimi $F$, Ariapanah $P$, Faizi $M$, Errors in preparation and administration of intravenous medications in the intensive care unit of a teaching hospital: An observational study, Aust Crit 2008; 21:110-116, doi: 10.1016/j.aucc.2007.10.004, PMID: 18387813

27. Van den Bemt PM, Fijn R, van der Voort PH, Frequency and determinants of drug administration errors in the intensive 
care unit, Crit Care Med, 2002; 30:846-850, doi: 10.1097/00003246-200204000-00022, PMID: 11940757

28. Tissot E, Cornette C, Demoly P, Medication errors at the administration stage in an intensive care unit, Intensive Care Med, 1999; 25:353-359, doi: 10.1007/s001340050857, PMID: 10342507

29. Kopp BJ, Erstad BL, Allen ME, Medication errors and adverse drug events in an intensive care unit: Direct observation approach for detection, Crit Care Med, 2006; 34:415-425, doi: $\quad 10.1097 / 01 . c c m .0000198106 .54306 . d 7$, PMID: 16424723

30. Bates DW, Leape LL, Cullen DJ, Effect of computerized physician order entry and a team intervention on prevention of serious medication errors, JAMA, 1998; 280: 13111316doi: 10.1001/jama.280.15.1311, PMID: 9794308

31. Paoletti RD, Suess TM, Lesko MG, Using bar-code technology and medication observation methodology for safer medication administration, Am J Health Syst Pharm, 2007; 64:536-543, doi: 10.2146/ajhp060140, PMID: 17322168

32. Guerrero RM, Nickman NA, Jorgenson JA, Work activities before and after implementation of an automated dispensing system, Am J Health Syst Pharm, 1996; 53:548-554, doi: 10.1093/ajhp/53.5.548, PMID: 8697015

33. Barker KN, Pearson RE, Hepler CD, Effect of an automated bedside dispensing machine on medication errors, Am J Hosp Pharm, 1984; 41:1352-1358, doi: https://academic.oup.com/ajhp/articleabstract/41/7/1352/ 5196554?redirectedFrom=PDF

34. Borel JM, Rascati KL, Effect of an automated, nursing unitbased drug-dispensing device on medication errors, Am J Health Syst Pharm, 1995; 52:1875-1879, doi: 10.1093/ajhp/52.17.1875, PMID: 8528848

35. Rodriguez-Gonzalez CG, Herranz-Alonso A, EscuderoVilaplana $V$, Robotic dispensing improves patient safety, inventory management, and staff satisfaction in an outpatient hospital pharmacy, J Eval Clinical Practice, 2018; 8: 1-8, doi: 10.1111/jep.13014.

36. Cherici CA, Remillard P, Implementation of a computerized medication administration record, Hosp Pharm, 1993; 28:193-198, PMID: 10124946

37. Leapfrog Group, Computer physician order entry (CPOE), www.leapfroggroup. org (accessed 2002 Jan 23), doi: $\underline{10.1177 / 1941874413495701}$

38. Larson $\mathrm{R}$, Blake J, Achieving order entry by physicians in a computerized medical record, Hosp Pharm, 1988; 23:551-3, PMID: 10287851

39. Bates DW, Using information technology to reduce rates of medication errors in hospitals, BMJ, 2000; 320:788-91, doi: $\underline{10.1136 / \mathrm{bmj} .320 .7237 .788}$

40. Massaro T, Introducing physician order entry at a major academic medical center: II, Impact on medical education, Acad Med, 1993; 68(1):25-30, DOI: 10.1097/00001888199301000-00003, PMID: 8447887

41. Chapuis C, Roustit M, Bal G, Automated drug dispensing system reduces medication errors in an intensive care setting, Critical Care Medicine, 2010; 38 (12): 2275-2281, doi: 10.1097/CCM.0b013e3181f8569b, PMID: 20838333
42. Shirley KL, Effect of an automated dispensing system on medication administration time, Am J Health Syst Pharm, 1999; 56: 1542-1545, DOI: 10.1093/ajhp/56.15.1542, PMID: 10478994

43. Manasse HR, Ferner RE, Anton C, Increase in US medicationerror deaths, Lancet, 1998; 351:16551656,doi:https://www.ncbi.nlm.nih.gov/books/NBK225182/ pdf/Bookshelf_NBK225182.pdf

44. Landrigan $\mathrm{CP}$, Parry $\mathrm{GJ}$, Bones $\mathrm{CB}$, Temporal trends in rates of patient harm resulting from medical care, New England Journal of Medicines, 2010; 363 (22): 2124-2134, DOI: 10.1056/NEJMsa1004404

45. Bates DW, Teich JM, Lee J, The impact of computerized physician order entry on medication error prevention, J Am Med Inform Ass, 1999; 6 (4): 313-321, doi: 10.1136/jamia.1999.00660313, PMID: 10428004

46. Poon EG, Keohane CA, Yoon CS, Effect of bar-code technology on the safety of medication administration, New England J Med, 2010, 362 (18): 1698-1707, DOI: 10.1056/NEJMsa0907115

47. Schimmel AM, Becker ML, Van Den Bout $T$, The impact of type of manual medication cart filling method on the frequency of medication administration errors: a prospective before and after study, Int J Nursing Studies, 2011; 48 (7): 791-797, DOI: $10.1016 /$ j.ijnurstu.2010.12.007

48. Barker KN, The effects of an experimental medication system on medication errors and costs. I Introduction and errors study, Am J Hospital Pharm, 1969; 26 (6): 324-333, DOI: https://doi.org/10.1093/ajhp/26.6.324

49. Paparella $S$, Automated medication dispensing systems: not error free, J Emergency Nursing, 2006; 32 (1): 71-74, DOI: 10.1016/j.jen.2005.11.004, PMID: 16439294

50. Flynn EA, Barker KN, Pepper GA, Comparison of methods for detecting medication errors in 36 hospitals and skilled nursing facilities, Am J Health-System Pharm, 2002; 59(5): 436-446, DOI: 10.1093/ajhp/59.5.436, PMID: 11887410

51. Cousein E, Mareville J, Lerooy A, Effect of automated drug distribution systems on medication error rates in a short-stay geriatric unit, J Eval Clinical Practice, 2014; 20: 678684, DOI: 10.1111/jep.12202, PMID: 24917185

52. Allan EL, Barker KN, Fundamentals of medication error research, Am J Hospital Pharm, 1990; 47 (3): 555-571, PMID: 2180287

53. Fontan JE, Maneglier V, Nguyen VX, Medication errors in hospitals: computerized unit dose drug dispensing system versus ward stock distribution system, Pharm World Sci, 2003; 25(3): 112-117, DOI: 10.1023/a:1024053514359, PMID: 12840964

54. Van den Bemt PM, Idzinga JC, Robertz H, Medication administration errors in nursing homes using an automated medication dispensing system, J Am Medical Informatics Asso, 2009; 16(4): 486-492, doi: 10.1197/jamia.M2959, PMID: 19390109

55. Thomas EJ, Studdert DM, Burstin HR, Incidence and types of adverse events and negligent care in Utah and Colorado, Med Care, 2000;38:261-271, DOI: 10.1097/00005650200003000-00003, PMID: 10718351 
56. Brennan TA, Leape LL, Laird N, Incidence of adverse events and negligence in hospitalized patients, Results of the Harvard Medical Practice Study I, N Engl J Med, 1991; 324: 370-375, DOI: 10.1056/NEJM199102073240604

57. Wilson RM, Runciman WB, Gibberd RW, The Quality in Australian Health Care Study, Med J Aust, 1995; 163: 458471, DOI: 10.5694/j.1326-5377.1995.tb124691.x, PMID: 7476634

58. Kaushal R, Bates DW, Landrigan C, Medication errors and adverse drug events in paediatric inpatients, J Am Med Assoc, 2001; 285: 2114-2120, doi:10.1001/jama.285.16.2114

59. Gandhi TK, Seger DL, Bates DW, Identifying drug safety issues: from research to practice, Int J Qual Health Care, 2000; 12: 69-76, DOI: 10.1093/intghc/12.1.69, PMID: 10733086

60. Lisby M, Nielsen LP, Mainz J. Errors in the medication process: frequency, type, and potential, Int J Quality in Health Care, 2005; 17: 15-22, DOI: 10.1093/intahc/mzi015 PMID: 15668306

61. Morrill GB, Barreuther C, Screening discharge prescriptions, Am J Hosp Pharm, 1988; 45: 1904-1905, PMID: 3228124

62. Wilkin TJ, Christopher LJ, Crooks J, Transcription errors in the drug information supplied from hospital to general practitioner, Health Bull (Edinb), 1978; 36: 13-16,doi https://www.semanticscholar.org/paper/Transcription-
errors-in-the-drug-information-from-WilkinDodd/722ccc721abd0cf3bbb4b785d5c4a4ca5769ace3

63. Wilson S, Warwick R, Chapman M, General practitioner hospital communications: A review of discharge summaries, J Qual Clin Pract, 2001; 21: 104-108, DOI: 10.1046/j.14401762.2001.00430.x

64. Folli HL, Poole RL, Benitz WE, Medication error prevention by clinical pharmacists in two children's hospitals, Pediatrics, 1987; 79: 718-722, PMID: 3575028

65. Dean BS, Barber ND, Schachter $M$, What is a prescribing error? Qual Health Care, 2000; 9: 232237, DOI: 10.1136/ahc.9.4.232 PMID: 11101708

66. Wirtz V, Taxis K, Barber ND, An observational study of intravenous medication errors in the United Kingdom and in Germany, Pharm World Sci, 2003; 25: 104-111, DOI: 10.1023/a:1024009000113 PMID: 12840963

67. Patterson ES, Cook RI, Render M, Improving patient safety by identifying side effects from introducing bar coding in medication administration, J Am Med Inform Assoc, 2002; 9:540-553, DOI: 10.1197/jamia.m1061 PMID: 12223506

68. Thornton PD, Simon S, Mathew TH, Towards safer drug prescribing, dispensing and administration in hospitals, J Qual Clin Pract, 1999; 19: 41-45, doi: https://doi.org/10.1046/i.1440-1762.1999.00290.x

Source of Support: The author(s) received no financial support for the research, authorship, and/or publication of this article.

Conflict of Interest: The author(s) declared no potential conflicts of interest with respect to the research, authorship, and/or publication of this article.

For any question relates to this article, please reach us at: editor@globalresearchonline.net New manuscripts for publication can be submitted at: submit@globalresearchonline.net and submit_ijpsrr@rediffmail.com 